ORIGINAL ARTICLE

\title{
Clinical and laboratory observations of tuberculosis at a Mumbai (India) clinic
}

\author{
D Gothi, J M Joshi
}

Postgrad Med J 2004;80:97-100. doi: 10.1136/pmj.2003.008185

See end of article for authors' affiliations

....................

Correspondence to:

Dr J M Joshi, Professor and

Head, Department of

Respiratory Medicine, B Y

L Nair Hospital, Mumbai

400008, India:

drjoshijm@email.com

Submitted 28 March 2003

Accepted 26 June 2003 Objectives: To study the positivity of sputum acid fast bacilli (AFB) smears in patients with pulmonary
tuberculosis using 24 hour sputum collection. To detect HIV seropositivity in patients suffering from tuberculosis using 24 hour sputum collection. To detect HIV seropositivity in patients suffering from
tuberculosis, and to analyse the pattern of tuberculosis disease in this subgroup. To determine the outcome of patients treated with directly observed therapy.

Setting: The tuberculosis referral unit of a tertiary care hospital.

Design: A total of 893 consecutive patients with tuberculosis, diagnosed between 1 November 2000 and 30 September 2002, were included in the study. An HIV test was performed in all patients, with adequate counselling and informed consent. Treatment was prescribed as per World Health Organisation treatment categories.

Results: Out of 893 patients with tuberculosis, 695 had pulmonary tuberculosis and 198 had extrapulmonary tuberculosis. Out of the 695 pulmonary tuberculosis patients, 673 (96.8\%) were sputum smear AFB positive. Overall, 71 patients (8.0\%) were HIV positive. The pattern of tuberculosis was the same in HIV seropositive and seronegative patients. Treatment outcome could be analysed in 112 out of 150 patients: 78 patients (70\%) were declared cured or completed treatment.

Conclusions: Sputum smear AFB could be a very sensitive test when a large quantity of sputum is used. The presence of HIV coinfection does not alter the clinical presentation. Only $70 \%$ of patients treated were cured/completed treatment, in spite of a strict directly observed therapy.
$\mathrm{T}$ uberculosis is one of the biggest enigmas facing mankind. The National Tuberculosis Programme of India, established in 1962, created an infrastructure for tuberculosis control throughout the country. A comprehensive review in 1992 by a committee of national and international experts observed that the programme had not achieved the desired results. ${ }^{12}$ One reason for failure of the previous programme in India was under-utilisation of microscopy and excessive reliance on radiology, which resulted in overdiagnosis of tuberculosis and wastage of scarce resources. The World Health Organisation (WHO) declared tuberculosis a global emergency in 1993 and recommended the Revised National Tuberculosis Control Programme (RNTCP) with directly observed therapy, short course (DOTS) as a solution for its control. ${ }^{34}$

Two important components of the DOTS strategy are good quality smear microscopy and directly observed therapy (DOT). ${ }^{5}$ A $5-10 \mathrm{ml}$ volume of sputum is recommended for the diagnosis of pulmonary tuberculosis. ${ }^{6-8}$ We routinely perform sputum smear acid fast bacilli (AFB) examination on a 24 hour sample in our reference laboratory, in order to obtain a large quantity of sputum. In developing countries, with the spread of HIV infection, the impact of tuberculosis has been intensified. The HIV and tuberculosis coepidemic has led to the development of strategies to decrease the burden of HIV related tuberculosis, comprising interventions against both tuberculosis and HIV. Hence, all patients with tuberculosis should be counselled for HIV testing. As per the RNTCP and DOTS strategy in India, ${ }^{5}$ treatment is to be fully supervised in the intensive phase and partially supervised in the continuation phase. However, the basic principle of DOT is that rifampicin should not be administered unsupervised. Hence, we give fully supervised treatment throughout therapy as recommended by the WHO.

The purposes of this study were thus to estimate, first, the sputum AFB smear positivity in patients with pulmonary tuberculosis using 24 hour sputum collection, second, the prevalence of HIV seropositivity and the pattern of disease in patients with pulmonary and extrapulmonary tuberculosis and, third, the outcome of treatment with a fully supervised DOT.

\section{PATIENTS AND METHODS}

A total of 893 patients diagnosed with tuberculosis after the implementation of RNTCP and DOT, between November 2000 and September 2002, were included in the study. Personal and demographic data, along with the type of tuberculosis and associated conditions, were recorded. Diagnosis of pulmonary tuberculosis was made by positive sputum AFB smear. The methods of smear preparation and examination were as prescribed by the WHO but, instead of spotovernight-spot samples, a 24 hour sputum collection was used to obtain a large quantity of sputum, as recommended by our reference microbiology laboratory. In patients with a negative sputum smear, diagnosis was established by sputum culture for Mycobacterium tuberculosis, bronchial aspirate smear or culture for $M$ tuberculosis, or transbronchial lung biopsy revealing caseating granuloma with or without a positive smear, and/or culture for $M$ tuberculosis. Extrapulmonary tuberculosis was diagnosed by fine needle aspiration cytology or biopsy showing caseating granuloma with or without a positive smear and/or culture for $M$ tuberculosis. One patient with suspected miliary tuberculosis required a trial of specific empiric antituberculosis treatment, and diagnosis was subsequently confirmed by liver biopsy. A complete blood count, tests for blood urea nitrogen and

Abbreviations: AFB, acid fast bacilli; DOT, directly observed therapy; DOTS, directly observed therapy, short course; ELISA, enzyme linked immunosorbent assay; RNTCP, Revised National Tuberculosis Control Programme; WHO, World Health Organisation 


\section{Table 1 WHO treatment categories}

\begin{tabular}{ll}
\hline Category & Regimen \\
\hline $\begin{array}{l}\text { I. New sputum positive or severely ill } \\
\text { sputum negative tuberculosis }\end{array}$ & 2(HERZ) 3+4(HR) 3 \\
$\begin{array}{ll}\text { II. Relapses, treatment failures, and } \\
\text { defaulters }\end{array}$ & 2 (SHERZ) 3+1(HERZ) 3+5(HRE) 3 \\
$\begin{array}{ll}\text { III. Sputum negative new cases, non- } \\
\text { serious extrapulmonary tuberculosis }\end{array}$ & 2(HRZ) 3+4(HR) 3 \\
\hline
\end{tabular}

$E$, ethambutol; $H$, isoniazide; $R$, rifampicin; $S$, streptomycin; $Z$, pyrazinamide.

blood glucose, a liver function test, and a rapid immunoassay test for HIV were performed in all patients. Client centred two step HIV prevention counselling was followed, and HIV testing was informed, voluntary, and consented. The information given to the patient included a description of the ways in which HIV is transmitted, the importance of obtaining test results, and the explicit procedures for doing so and the benefits and consequences. In the second session, when the results of the HIV test were available, the counsellor discussed the test results, asked the client to describe the risk reduction steps attempted, helped the patient to identify and commit to additional behavioural steps, and provided appropriate referrals. HIV seropositivity was diagnosed by a three step rapid immunoassay. In the first step a micro-enzyme linked immunosorbent assay (ELISA) ( $\mathrm{J}$ Mitra \& Co Ltd) was performed. If micro-ELISA was positive, spot by HIV tri-dot (Biotech Inc) and spot by Comb-aids-recombinant protein and synthetic peptides (Span Diagnostic Ltd) were performed; the patient was considered HIV positive only if all three tests were positive.

All the patients were prescribed treatment as per WHO treatment categories, as shown in table 1. Of the 893 diagnosed cases, 723 patients were referred to their nearest DOT centre, and 20 patients were not willing to participate in DOT therapy and were treated with a fixed drug combination. This left 150 patients residing in the vicinity of our hospital who were treated at our DOT centre and whose treatment was fully supervised throughout. DOT included the involvement of a treatment organiser or a health visitor, who supervised each dose and visited patients at home if they failed to follow up. For the patients with pulmonary tuberculosis and positive initial sputum smears, sputum examination was repeated at $2-3,4-5$, and $6-8$ months of treatment depending on WHO treatment categories. Treatment outcome was recorded as cured, completed treatment, defaulted, failed, or died based on the definitions given by the WHO (table 2 ). Of the 150 patients treated at our centre, outcome could be analysed in 112; the remaining 38 patients had not completed treatment at the time of data analysis.

\begin{tabular}{ll} 
Table 2 & Definitions \\
\hline Cure & $\begin{array}{l}\text { Patient who is smear negative at (or } 1 \text { month before) } \\
\text { the completion of treatment and on at least one } \\
\text { previous occasion }\end{array}$ \\
$\begin{array}{l}\text { Treatment } \\
\text { completed }\end{array}$ & $\begin{array}{l}\text { stient who has completed treatment but for whom } \\
\text { occasions before the completion of treatment }\end{array}$ \\
Treatment failure $\begin{array}{l}\text { Patient who remains or becomes smear positive } \\
5 \text { months or more after starting treatment }\end{array}$ & $\begin{array}{l}\text { Patient whose treatment has been interrupted for more } \\
\text { than } 2 \text { consecutive months before the end of the course } \\
\text { of treatment }\end{array}$ \\
Defaulted &
\end{tabular}

\section{RESULTS}

Our 893 patients with tuberculosis had an age range of 12 to 72 years (mean 42 years); $536(60 \%)$ were males and 357 $(40 \%)$ were females. In total, 695 patients were suffering from pulmonary tuberculosis, and 198 patients were diagnosed with extrapulmonary tuberculosis. Out of the 695 pulmonary tuberculosis patients, $673(96.8 \%)$ were sputum smear positive for AFB, and only 22 (3.2\%) were sputum smear negative. In 10 of the smear negative cases diagnosis was made by positive culture for $M$ tuberculosis, and in six cases bronchial aspirate or transbronchial lung biopsy was positive for AFB. In the remaining six patients antituberculosis treatment had already been started at the time of referral, and, as there was clinical improvement, treatment was continued.

The commonest form of extrapulmonary tuberculosis was tuberculous lymphadenopathy, followed by pleural effusion (table 3). Six cases of miliary tuberculosis were diagnosed on transbronchial lung biopsy, while one patient with miliary tuberculosis required a trial of specific empiric antituberculosis therapy; diagnosis was subsequently confirmed by liver biopsy.

We found that 67 patients $(7.5 \%)$ had diabetes mellitus, and 71 patients $(8.0 \%)$ tested positive for HIV. Of the 71 patients with HIV seropositivity, 54 (76.1\%) had pulmonary tuberculosis and only two of them $(3.7 \%)$ were smear negative; nine patients $(12.7 \%)$ were found to have pleural effusion, five $(7.0 \%)$ had tuberculosis lymphadenopathy, one (1.4\%) had both pleural and pericardial effusions, and two patients $(3.7 \%)$ had miliary tuberculosis. Comparisons of pulmonary and extrapulmonary tuberculosis in HIV seropositive and seronegative patients are given in tables 4 and 5 .

Out of 150 patients who were treated at our centre, only 112 could be analysed, as the others had not completed the treatment at the time of data analysis. In all these patients the entire treatment, that is, intensive phase and continuation phase, was fully supervised. Overall, 78 patients $(70 \%)$ were cured or completed treatment, 12 patients (11\%) failed to respond, 16 patients (14\%) defaulted, and six patients (5\%) died during treatment.

\section{DISCUSSION}

The most significant finding of our study was that $96.8 \%$ of patients with pulmonary tuberculosis had positive sputum smears for AFB. Various studies have reported sputum smear positivities ranging from $39 \%$ to $74 \%{ }^{9-12}$ The reason for the high sputum smear positivity in our study could be the larger quantity of sputum (24 hour) submitted for AFB smear examination. A recent study by Warren et al documented $92 \%$ sputum smear AFB positivity when more than $5 \mathrm{ml}$ of

\begin{tabular}{|ll|}
\hline \multicolumn{2}{l}{$\begin{array}{l}\text { Table } 3 \\
\text { (HIV and non-HIV combined; } \mathrm{n}=198 \text { ) }\end{array}$} \\
\hline & $\begin{array}{l}\text { No of } \\
\text { cases }\end{array}$ \\
Type & 87 \\
\hline Pleural effusion & 97 \\
Lymphadenopathy & 82 \\
Cervical & 9 \\
Mediastinal & 3 \\
Mediastinal and cervical & 1 \\
Tuberculous meningitis and tuberculous & 1 \\
lymphadenopathy & 1 \\
Mediastinal lymph node with pulmonary lesion & 1 \\
Tuberculous lymphadenopathy with pleural & 1 \\
effusion & 7 \\
Miliary tuberculosis & 7 \\
\hline
\end{tabular}


Table 4 Comparison of HIV status and pulmonary/ extrapulmonary tuberculosis

\begin{tabular}{llll}
\hline Type of tuberculosis & HIV negative (\%) & HIV positive (\%) & Total \\
\hline Pulmonary & $641(78)$ & $54(76)$ & 695 \\
Sputum smear negative & $20(3)^{*}$ & $2(4)^{*}$ & 22 \\
pulmonary & & $17(24)$ & 198 \\
Extrapulmonary & $181(22)$ & 71 & 893 \\
Total & 822 &
\end{tabular}

sputum was used for smear diagnosis of pulmonary tuberculosis. ${ }^{7}$ Use of 24 hour sputum appears to provide a sufficient volume for detection of AFB intermittently shed into respiratory secretions. A volume of $5-10 \mathrm{ml}$ of sputum is recommended for the diagnosis of pulmonary tuberculosis, ${ }^{6}$ but most clinical laboratories do not comply with this guideline. ${ }^{8}$ Although AFB smear examination is an extremely simple test carried out in most laboratories, it requires dedicated effort to obtain accurate results. In developing countries, the AFB sputum smear may be the only test available for diagnosis. ${ }^{13}$ Hence, every effort should be made to establish reliable laboratories with adequate quality control.

Fine needle aspiration cytology or biopsy could establish the diagnosis in most cases of extrapulmonary tuberculosis. One patient with miliary tuberculosis required a trial of specific empiric antituberculosis therapy; diagnosis was subsequently confirmed by liver biopsy. Specific empiric antituberculosis therapy involves treatment with three specific antituberculosis drugs, isoniazid, pyrazinamide and ethambutol, in the absence of bacteriological or histological proof of tuberculosis. ${ }^{14}$ Rifampicin, being a broad spectrum antibiotic, is not included in empiric treatment as fever due to infections other than tuberculosis may respond to treatment, leading to misdiagnosis. Once the fever responds to specific empiric antituberculosis therapy, rifampicin is added to the treatment.

In this study, $8 \%$ of patients with tuberculosis were HIV seropositive. Various studies from India have reported rates of HIV seropositivity ranging from $0.4 \%$ to $4.9 \%$, with a rising trend..$^{15-18}$ Two recent studies, however, have reported HIV seropositivity in pulmonary tuberculosis patients to be $6.9 \%$ and $10 \%$, respectively. ${ }^{19}{ }^{20}$ The incidences of extrapulmonary tuberculosis in HIV seronegative and HIV seropositive patients in our study were almost the same, at $22 \%$ and $24 \%$, respectively. Smear negative pulmonary tuberculosis was observed in $3.2 \%$ of HIV seronegative patients and in $3.7 \%$ of the HIV seropositive group. This indicates that the pattern of presentation of tuberculosis in HIV seropositive patients is the same as that in HIV seronegative patients. This finding has been highlighted in other recent reports. ${ }^{21}{ }^{22}$ There is a close epidemiological link between HIV and tuberculosis, ${ }^{23}{ }^{24}$ despite which the public health programmes have largely remained separate. The WHO has recommended that HIV and tuberculosis should be linked by voluntary counselling and testing for HIV in patients with tuberculosis. ${ }^{24}$ The benefits of voluntary counselling and testing for HIV in tuberculosis patients include early diagnosis, referral for appropriate clinical care, and support for those testing HIV positive.

DOT, which ensures that the patient takes medication under the direct supervision of a health assistant, has emerged as a solution to the problem of non-compliance and has been proved effective in various parts of the world. ${ }^{4}$ While all the patients at our centre received fully supervised treatment as recommended by the WHO, this is not routine practice under Indian RNTCP. Recent studies have shown
Table 5 HIV status and types of extrapulmonary tuberculosis

\begin{tabular}{llll}
\hline & HIV negative (\%) & HIV positive (\%) & Total \\
\hline Lymphadenopathy & $92(51)$ & $5(29)$ & 97 \\
Pleural effusion & $78(43)$ & $9(53)$ & 87 \\
Miliary & $5(3)$ & $2(12)$ & 7 \\
Other & $6(3)$ & $1(6)$ & 7 \\
Total & 181 & 17 & 198 \\
\hline & & \\
\hline
\end{tabular}

that only one out of five DOTS workers ensures supervised swallowing of the doses, while others either ask the patient to go to the next room or hand over the entire weekly pack to be taken at home. ${ }^{25} 26$ So, what started off as DOTS ends up being POTS (partially observed treatment, short course) or even KNOTS (knowing but not observing treatment, short course)..$^{25}$

Despite claims of high cure rates when using DOT under RNTCP, ${ }^{5}$ only $70 \%$ of patients in our study were cured or completed treatment despite fully supervised therapy. The results are similar to those observed in some of the recent case-control studies. ${ }^{27} 28$ Reasons for the lower cure or completion rate in our study could be that the reliable microscopy laboratory used by our centre was better able to detect treatment failure, that there was a high default rate owing to the availability of loose drugs and loss of cases to private doctors, or that the cure rates claimed by the RNTCP are of questionable reliability.

Patients who were not willing to participate in DOTS were treated with a fixed drug combination. It is important to use methods of drug administration that avoid the danger of the use of rifampicin alone. Hence, if DOT is not possible, self administered treatment with a fixed drug combination could be used. Self supervised treatment with adequate counselling has shown results comparable to DOTS..$^{29}{ }^{30}$ The effectiveness of DOT therefore remains unclear, and further operational research is needed.

\section{Authors' affiliations}

D Gothi, J M Joshi, Department of Respiratory Medicine, T N Medical College, B Y L Nair Hospital, Mumbai, India

\section{REFERENCES}

1 Directorate General of Health Services and Family Welfare. Tuberculosis control-India. 12 October 2002 (www.tbcindia.org).

2 Grzybowski S. Drugs are not enough. Failure of short-course chemotherapy in a district in India. Tuberc Lung Dis 1993;74:145-6.

3 World Health Organisation. Report on the TB epidemic. WHO/TB/97.224. Geneva: WHO, 1997.

4 World Health Organisation. A clinical manual for South East Asia. Treatment of tuberculosis-guidelines for national programme. WHO/TB/96.200. Geneva: WHO, 1997.

5 Khatri GR. The Revised National Tuberculosis Control Programme: a status report on first 1,00,000 patients. Indian J Tuberc 1999;46:157-66.

6 Metchock BG, Nolte FS, Wallace RJ. Mycobacterium. In: Murray PR, Baron EJ, Pfallerm MA, Tenover FC, Yokken RH, eds. Manual of clinical microbiology. 7th Ed. Washington, DC: ASM Press, 1999:399-437.

7 Warren JR, Bhattacharya M, De Almeida KN, et al. A minimum $5.0 \mathrm{ml}$ of sputum improves the sensitivity of acid-fast smear for Mycobacterium tuberculosis. Am J Respir Crit Care Med 2000;161:1559-62.

8 Della-Latta P, Whittier S. Comprehensive evaluation of performance, laboratory application, and clinical usefulness of two direct amplification techniques for detection of Mycobacterium tuberculosis complex. Am J Clin Pathol 1998;110:301-10.

9 Kim TC, Blackman RS, Heatwole KM, et al. Acid-fast-bacilli in sputum smears of patients with pulmonary tuberculosis. Am Rev Respir Dis 1984;129:264-8.

10 Dutt AK, Stead WW. Short course chemotherapy. The Arkansas experience. Chest 1981;80:724-7.

11 Gunnels JJ, Bates JH, Swindoll H. Infectivity of sputum positive tuberculosis patients on chemotherapy. Am Rev Respir Dis 1974; 109:323-30.

12 Narain R, Subba Rao MS, Chandrashekhar $P$, et al. Microscopy positive and microscopy negative cases. Am Rev Respir Dis 1971;103:761-3. 
13 Ormerod LP. Respiratory tuberculosis. In: Davies PDO ed Clinical tuberculosis. 2nd Ed. London: Chapman \& Hall, 1998:155-74.

14 Anglaret X, Saba J, Perronne C, et al. Empiric antituberculosis treatment: benefits for earlier diagnosis and treatment of tuberculosis. Tuberc Lung Dis 1994:75:334-50

15 Mohanty KC, Pasi RB. Incidence of HIV infection in TB. Proceedings of the National Conference on TB and Chest Disease. Mumbai, 1992.

16 Benvelikar JN. HIV seropositivity in hospitalized patients in Delhi. Indian J Tuberc 1997:44:17-20.

17 Vasade VV. HIV infection among tuberculosis patients. Indian J Tuberc 1997;44:97-8

18 Gupta PR. TB in HIV seropositive patients in Rajasthan. Lung India 1998:16:147-9.

19 Rathi PM, Amarapurkar DN, Parikh SS, et al. Impact of human immunodeficiency virus infection on abdominal TB in Western India. J Clin Gastroenterol 1997;24:43-8

20 Corbett EL, Watt CJ, Walker N, et al. The growing burden of tuberculosis global trends and interactions with the HIV epidemic. Arch Intern Med 2003:163:1009-21.

21 Perlman DC, el-Sard MW, Nelson ET, et al. Chest radiographic pattern in pulmonary tuberculosis by degree of human immunodeficiency virus related immunosuppression: the Terry Beirn progress for clinical research in AIDS (CPCRA). Clin Infect Dis 1997;25:242-6.

22 Halvir DV, Barnes PF. Tuberculosis in patients with human immunodeficiency virus infection. N Engl J Med 1999;340:367-73.
23 Advisory Committee for the Elimination of Tuberculosis. Tuberculosis and human immunodeficiency virus infection: recommendation of the Advisory Committee for the Elimination of Tuberculosis (ACET). MMWR Morb Mortal Wkly Rep 1989:38:236-8, 243-50.

24 Godfrey-Faussett P, Maher D, Mukadi YD, et al. How human immunodeficiency virus voluntary testing can contribute to tuberculosis control. Bull World Health Organ 2002;80:939-45.

25 Kaul S. The Revised National TB Control Programme and the DOTS strategy. Excerpts from an observational study in three districts. 1998 (www.ctrlaltesc.org/fighttb/02/02/11/102207.shtml).

26 Balasubramanium VN, Dommen K, Samuel R. DOT or not? Direct observation of anti tuberculosis treatment and patient outcomes, Kerala State India. Int J Tuberc Lung Dis 2000;4:409-13.

27 Santha T, Garg R, Frieden TR, et al. Risk factors associated with default, failure and death among tuberculosis patients treated in a DOTS programme in Tiruvallur District, South India, 2000. Int J Tuberc Lung Dis 2002;6:780-8.

28 Walley JD, Khan MA, Newell JN, et al. Effectiveness of the direct observation component of DOTS for tuberculosis: a randomized controlled trial in Pakistan. Lancet 2001;357:664-9.

29 Tandon M, Gupta M, Tandon S, et al. DOTS versus self-administered therapy (SAT) for patients of pulmonary tuberculosis: a randomized trial at a tertiary care hospital. Indian J Med Sci 2002;56:19-21.

30 Zwarenstein $M$, Schoeman $\mathrm{JH}$, Vundule $\mathrm{C}$, et al. Randomized controlled trial of self-supervised and directly observed treatment of tuberculosis. Lancet 1998;352:1340-3 